\title{
Compact Penta-Band Dual ZOR Antenna for Mobile Applications
}

\author{
Jae-Gon Lee, ${ }^{1}$ Dong-Jin Kim, ${ }^{2}$ and Jeong-Hae Lee ${ }^{3}$ \\ ${ }^{1}$ Metamaterial Electronic Device Research Center, Hongik University, Seoul 04066, Republic of Korea \\ ${ }^{2}$ LG Electronics, Seoul 08500, Republic of Korea \\ ${ }^{3}$ Department of Electronic Information and Communication Engineering, Hongik University, Seoul 04066, Republic of Korea
}

Correspondence should be addressed to Jeong-Hae Lee; jeonglee@hongik.ac.kr

Received 5 February 2016; Accepted 17 May 2016

Academic Editor: Elena De Cos

Copyright (C) 2016 Jae-Gon Lee et al. This is an open access article distributed under the Creative Commons Attribution License, which permits unrestricted use, distribution, and reproduction in any medium, provided the original work is properly cited.

\begin{abstract}
A compact penta-band dual zeroth order resonator (ZOR) antenna with band-stop filter is proposed for mobile applications. The ZOR antenna is designed with modified mushroom-like structures extended on nonground region to obtain good efficiency and broad bandwidth. This modified mushroom-like structure is confirmed as double negative (DNG) transmission line by full wave simulated dispersion relation. Moreover, a bended patch and a band-stop filter (BSF) are employed to increase efficiency and bandwidth, respectively. The length of each antenna is about $\lambda_{0} / 10$ at the resonant frequencies of $900 \mathrm{MHz}$ and $1800 \mathrm{MHz}$, respectively. The overall dimension of the antenna is $54.4 \mathrm{~mm}$ (length) $\times 4 \mathrm{~mm}$ (width) $\times 5 \mathrm{~mm}$ (height). The total efficiencies in low and high bands are measured more than $40 \%$ and $70 \%$, respectively.
\end{abstract}

\section{Introduction}

Nowadays, as mobile handsets have a full display screen and a slim form factor, volumes for antennas are compact. Furthermore, to satisfy the various demands for wireless services such as $2 \mathrm{G}, 3 \mathrm{G}$, and long term evolution (LTE), the antenna for mobile handsets has to cover multiband and broadband. A planar inverted-F antenna (PIFA) and a monopole antenna are the most popular antennas for wireless performance of mobile handsets [1]. However, they have a drawback of bulky structure due to quarter wavelength and a degradation of performance due to a current cancellation by image current as volumes for antennas are more compact.

The zeroth order resonator (ZOR) antenna [2,3] could be one of the attractive candidates to design compact antenna structure because its resonance frequency is independent of physical length. The ZOR is the unique characteristic of metastructure transmission lines such as double negative (DNG) [4], epsilon negative (ENG), and mu negative (MNG) transmission line [5]. For a decade, ZOR antenna concepts for mobile handsets have been introduced $[6,7]$. However, the proposed antennas of previous papers could not cover penta-band composed of global system for mobile communications (GSM 850/900/1800/1900, 824 894 MHz/880 $960 \mathrm{MHz} / 1710 \sim 1880 \mathrm{MHz} / 1850 \sim 1990 \mathrm{MHz})$ and wideband code division multiple access (WCDMA, 1920 2170 MHz)

Therefore, a compact DNG dual ZOR antenna is presented for penta-band mobile handsets in this paper. The antenna is composed of big and small patches with grounded lines to cover low and high band, respectively. Moreover, we have designed mushroom-like ZOR antenna that has extended grounded line on a nonground region, bended patch to improve performance of antenna, and band-stop filter (BSF) to increase bandwidth of the low band. Design procedure of the antenna is described and the simulated and measured results are compared in the following.

\section{Design of Dual ZOR Antenna}

An infinitesimal circuit model of lossless $(R=0$ and $G=$ 0 ) double negative (DNG) transmission line is represented as the combination of a per-unit length series inductance 


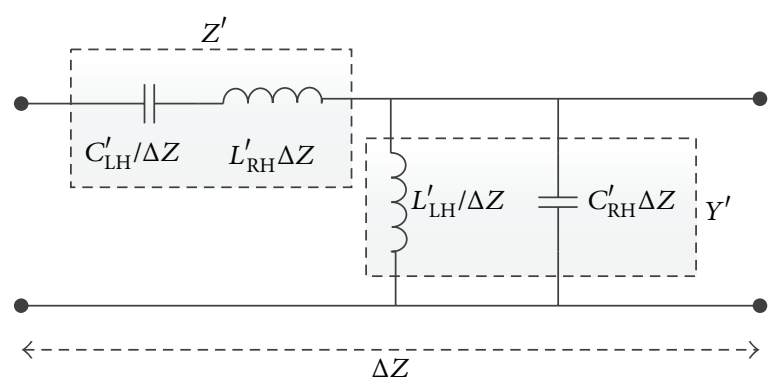

FIGURE 1: Infinitesimal circuit model of lossless DNG transmission line.

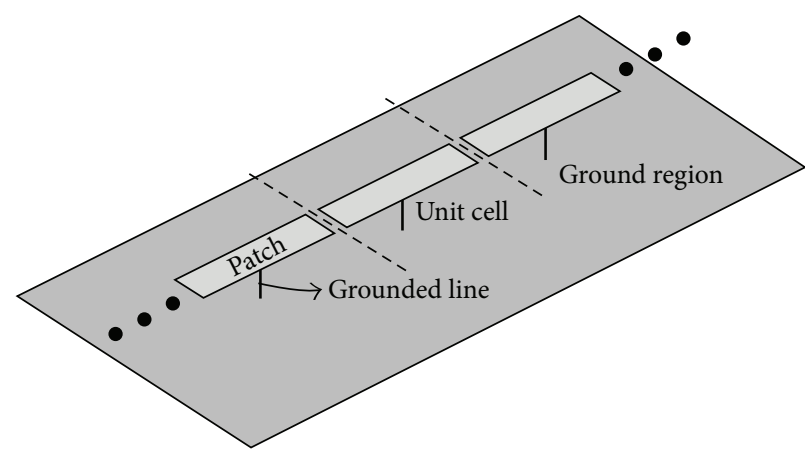

(a)

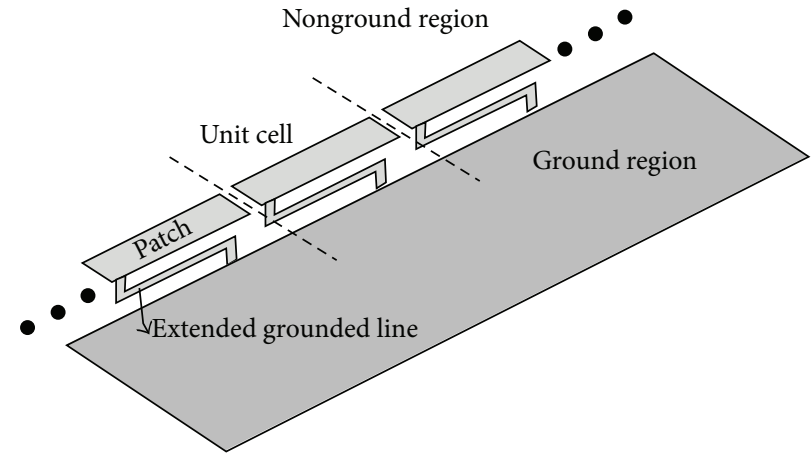

(b)

FIGURE 2: Structure for a DNG transmission line. (a) Conventional mushroom. (b) Modified mushroom.

$\left(L_{\mathrm{RH}}^{\prime}\right)$, shunt capacitance $\left(C_{\mathrm{RH}}^{\prime}\right)$ and a times-unit length series capacitance $\left(C_{\mathrm{LH}}^{\prime}\right)$, and shunt inductance $\left(L_{\mathrm{LH}}^{\prime}\right)$, as shown in Figure 1. By applying Bloch-Floquet theory to the equivalent circuit of unit cell, the analytic dispersion equation of DNG transmission line can be obtained by [8]

$$
\cos \beta d=1-\frac{1}{2}\left(\frac{\omega_{\mathrm{LH}}^{2}}{\omega^{2}}+\frac{\omega^{2}}{\omega_{\mathrm{RH}}^{2}}-\left|\frac{\omega_{\mathrm{sh}}^{2}}{\omega_{\mathrm{RH}}^{2}}+\frac{\omega_{\mathrm{se}}^{2}}{\omega_{\mathrm{RH}}^{2}}\right|\right),
$$

where $\omega_{\mathrm{RH}}=1 / \sqrt{C_{\mathrm{RH}} L_{\mathrm{RH}}}, \omega_{\mathrm{LH}}=1 / \sqrt{C_{\mathrm{LH}} L_{\mathrm{LH}}}, \omega_{\mathrm{se}}=$ $1 / \sqrt{C_{\mathrm{LH}} L_{\mathrm{RH}}}, \omega_{\mathrm{sh}}=1 / \sqrt{C_{\mathrm{RH}} L_{\mathrm{LH}}}$, and $d$ is length of unit cell. $C_{\mathrm{LH}}\left(C_{\mathrm{LH}}^{\prime} / d\right), C_{\mathrm{RH}}\left(C_{\mathrm{RH}}^{\prime} d\right), L_{\mathrm{RH}}\left(L_{\mathrm{RH}}^{\prime} d\right)$, and $L_{\mathrm{LH}}\left(L_{\mathrm{LH}}^{\prime} / d\right)$ are the series capacitance, shunt capacitance, series inductance, and shunt inductance in terms of the real lumped components (in $F$ and $H$ ), respectively. The resonance modes of the DNG transmission line can be obtained by

$$
\beta_{n} d=\frac{n \pi d}{l}=\frac{n \pi}{N} \quad(n=0, \pm 1, \pm 2, \ldots, \pm(N-1)),
$$

where $N$ and $l$ are the number of unit cell and physical length of resonator, respectively. When $n$ equals to 0 , especially, zeroth order resonance mode can be excited. If the ZOR antenna has open-ended boundary, input impedance of ZOR is expressed as $1 /\left(j \omega C_{\mathrm{RH}} N+N / j \omega L_{\mathrm{LH}}\right)[2]$. $Z_{\text {in }}$ exhibits the impedance of the $\mathrm{LC}$ antiresonant circuit with an inductance of $L_{\mathrm{LH}} / N$ and a capacitance of $N C_{\mathrm{RH}}$. Therefore, resonant frequency of the ZOR is $f_{\mathrm{sh}}\left(f_{\mathrm{sh}}=1 /\left(2 \pi \sqrt{C_{\mathrm{RH}} L_{\mathrm{LH}}}\right)\right)$.

A mushroom structure is the most basic and popular for DNG transmission line, as shown in Figure 2(a) [9]. However, zeroth order resonance generated from the conventional mushroom structure has a little poor efficiency due to insufficient effective volume for radiation. Therefore, the patches of main radiation part are protruded from ground region using extended grounded line to obtain maximum effective volume of antenna, as shown in Figure 2(b). Figures 3(a) and 3(b) show the structure and photograph of the dual ZOR antenna with band-stop filter, respectively. The big mushroom for a low band is composed of patch $(32 \mathrm{~mm} \times 9.5 \mathrm{~mm})$ and grounded line $(18 \mathrm{~mm})$. The small mushroom for a high band is also composed of patch $(17 \mathrm{~mm} \times 9.5 \mathrm{~mm})$ and grounded line $(15 \mathrm{~mm})$. Feeding structure is implemented by gap of $0.2 \mathrm{~mm}$ and its length is $5 \mathrm{~mm}$. The length of each antenna is about $\lambda_{0} / 10$ at the resonant frequencies of $900 \mathrm{MHz}$ and $1800 \mathrm{MHz}$, respectively. Overall dimension of the antenna is $54.4 \mathrm{~mm}$ (length) $\times 4 \mathrm{~mm}$ (width) $\times 5 \mathrm{~mm}$ (height) and dimension of main board is $140 \mathrm{~mm}$ (length) $\times 70 \mathrm{~mm}$ (width). Antenna carrier is FR4 substrate with a permittivity of 4.4 and a loss tangent of 0.02 .

Furthermore, the patches are bended to get broader radiation area so that maximum efficiency can be obtained.

To confirm the characteristic of DNG transmission line, we have calculated analytic and simulated dispersion diagram of both the modified mushroom structure using (1) and commercial simulator (Ansys's HFSS), respectively. The values of components in (1) are extracted from the simulated results of two-port network for calculation of analytic dispersion diagram. Also, the simulated dispersion diagram can be extracted from $S$-parameters of each unit cell at the driven model solution one-dimensionally. From Figure 4, 


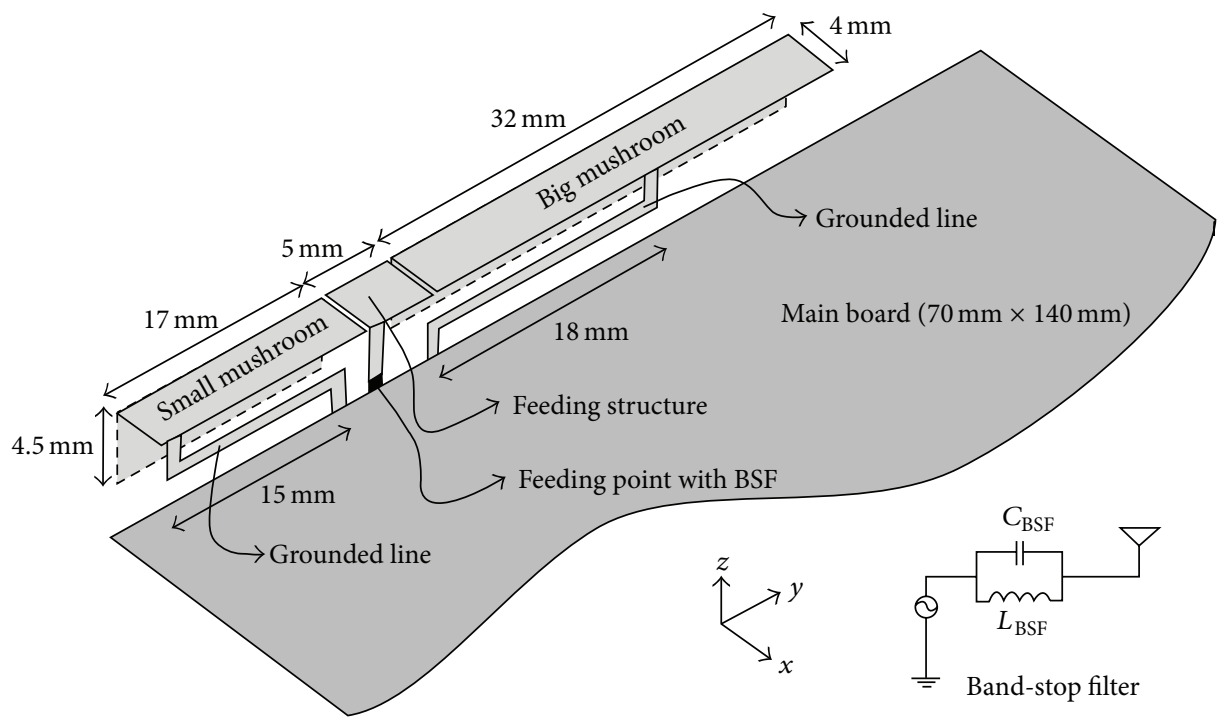

(a)

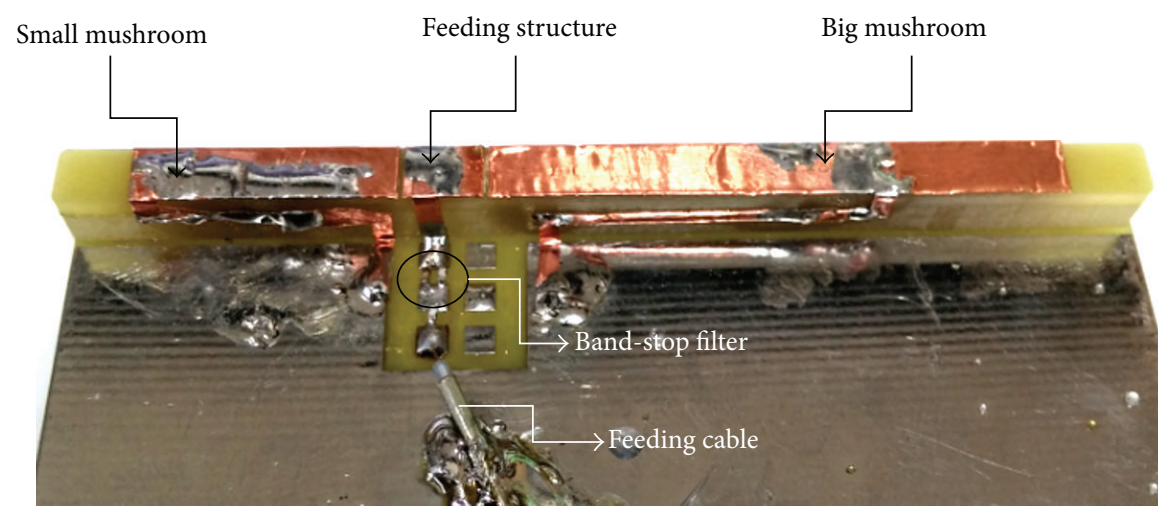

(b)

Figure 3: (a) Structure and (b) photograph of the proposed dual ZOR antenna.

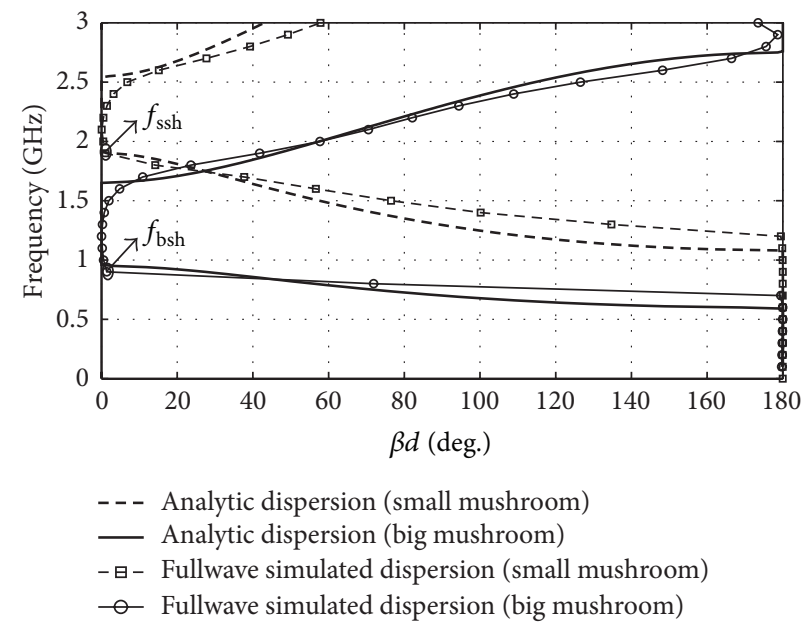

FIgURE 4: Analytic and fullwave simulated dispersion diagram of both modified mushroom structures. 


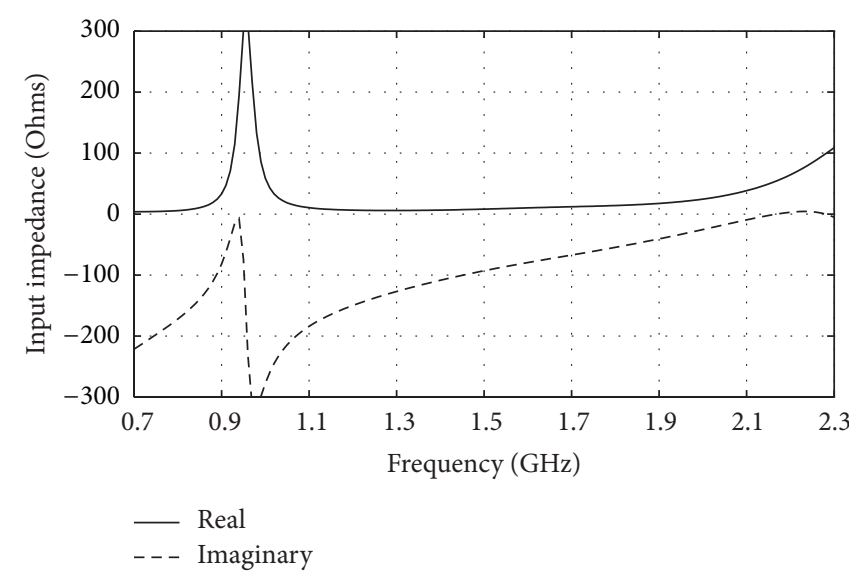

(a)

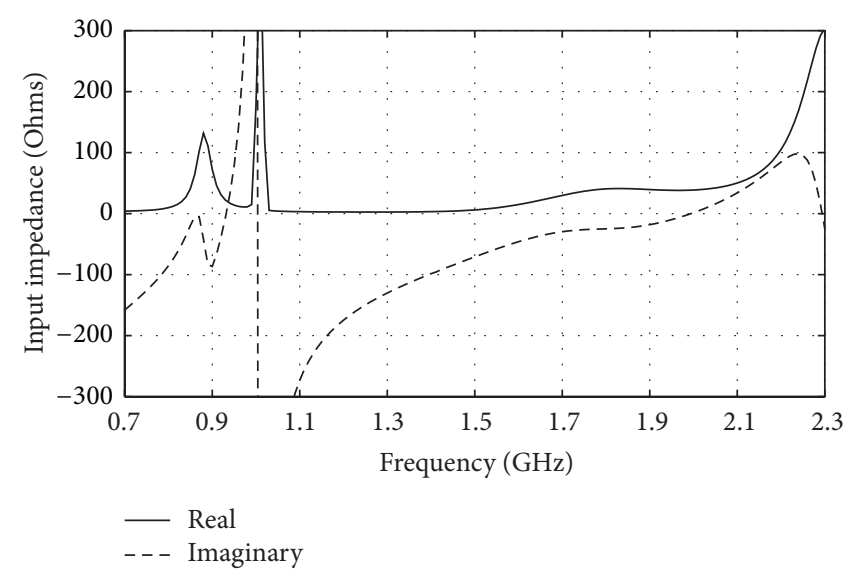

(c)

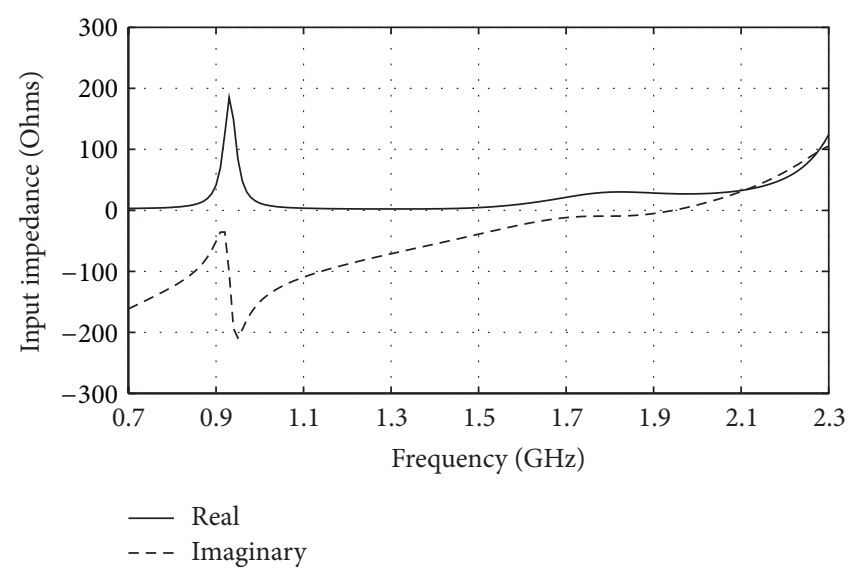

(b)

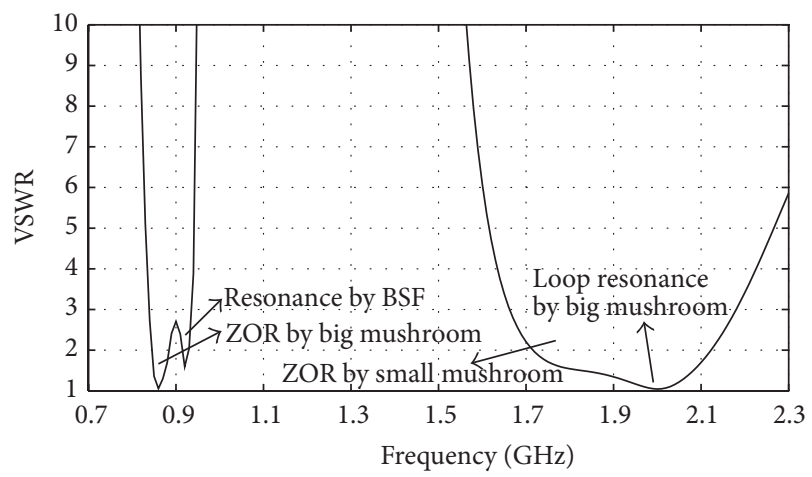

(d)

FIGURE 5: (a) Simulated input impedance of the single ZOR. (b) Simulated input impedance of the dual ZOR. (c) Simulated input impedance of the dual ZOR with BSF. (d) VSWR of the dual ZOR with BSF.

DNG regions in case of big and small modified mushroom are simulated $0.7 \sim 0.8 \mathrm{GHz}$ and $1.25 \sim 1.85 \mathrm{GHz}$, respectively. It has been expected that zeroth resonance frequencies ( $f_{\text {bsh }}$ and $f_{\text {ssh }}$ ) of big and small modified mushroom structure are $0.8 \mathrm{GHz}$ and $1.85 \mathrm{GHz}$, respectively, because $f_{\text {se }}\left(f_{\text {se }}=\right.$ $\left.1 /\left(2 \pi \sqrt{C_{\mathrm{LH}} L_{\mathrm{RH}}}\right)\right)$ is larger than $f_{\mathrm{sh}}$. The resonant frequency of ZOR antenna with open-ended boundary can be controlled by $C_{\mathrm{RH}}$ and $L_{\mathrm{LH}}$ values. The $C_{\mathrm{RH}}$ and $L_{\mathrm{LH}}$ values are related with a size of patch and a length of grounded line, respectively. If a patch of the mushroom is bigger or a length of the grounded line is longer, zeroth order resonance could be downshifted.

Design procedure of the antenna is described in the following. First, we have simulated a single ZOR antenna using big modified mushroom. Its resonant frequency is $860 \mathrm{MHz}$ and the second resonance (one wavelength loop resonance) occurs at $2200 \mathrm{MHz}$, as shown in Figure 5(a). It is difficult to control the second resonance frequency to fit the requested band $(1710 \sim 2170 \mathrm{MHz})$ because the zeroth order resonance frequency in the low band is also changed. Therefore, a small modified mushroom has to be added to big mushroom structure to control independently resonant frequency and to design broad bandwidth for high band, as shown in Figure 5(b). However, we have known that the bandwidth for low band is still narrow. Thus, band-stop filter (BSF) is applied to matching network to obtain additional resonance at low band and is designed using chip inductor of $4.5 \mathrm{nH}$ and chip capacitor of $5 \mathrm{pF}$ with parallel-series type. The BSF circuit has a center frequency at $1010 \mathrm{MHz}$ and is crucial in generating a new mode, with slightly affecting other existing modes, as shown in Figure 5(c). As a result, bandwidths of $3: 1$ VSWR in low band are simulated as $110 \mathrm{MHz}(820 \sim 930 \mathrm{MHz})$. In high band, bandwidths of $3: 1$ VSWR are simulated as $510 \mathrm{MHz}(1680 \sim 2190 \mathrm{MHz})$. Therefore, the antenna covers penta-band (GSM 850/900/1800/1900, 824 894 MHz/880 $960 \mathrm{MHz} / 1710 \sim 1880 \mathrm{MHz} / 1850 \sim 1990 \mathrm{MHz})$ and wideband code division multiple access (WCDMA, 1920 2170 MHz), as shown in Figure 5(d). To confirm the resonance characteristic at each resonant frequency, we have plotted the simulated surface current distributions. As shown in Figure 6, the surface currents at $870 \mathrm{MHz}$ and $1750 \mathrm{MHz}$ concentrate on extended grounded line due to ZOR mode, and loop resonant 


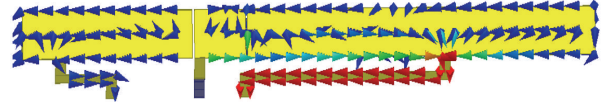

(a)

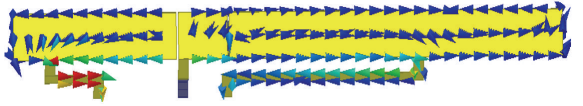

(b)

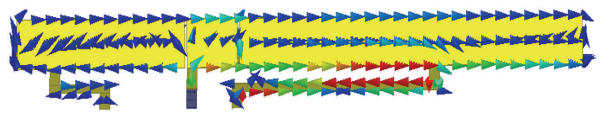

(c)

FIGURE 6: Simulated surface current distributions. (a) $870 \mathrm{MHz}$ : ZOR by big mushroom. (b) 1750 MHz: ZOR by small mushroom. (c) $2000 \mathrm{MHz}$ : loop resonance by big mushroom.

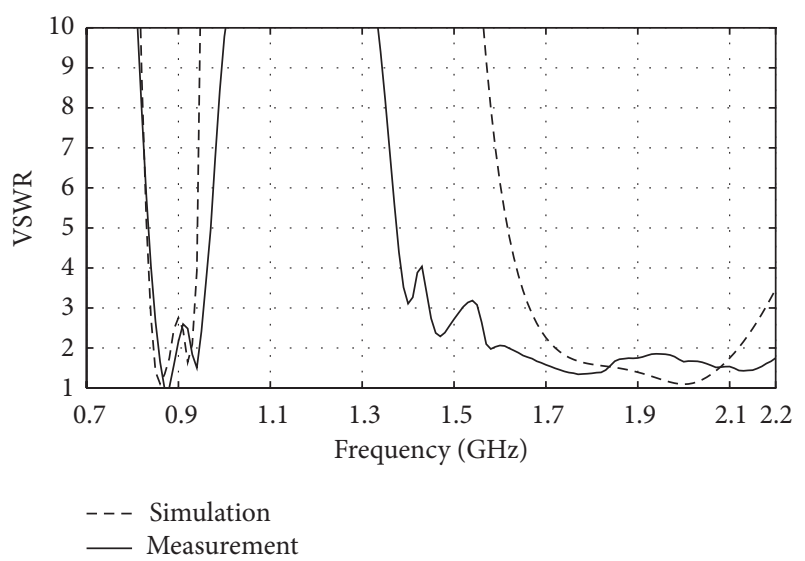

FIGURE 7: Simulated and measured VSWR of dual ZOR antenna with BSF.

mode at $2000 \mathrm{MHz}$ comes from one wavelength loop along path from a feed to a grounded line of the big mushroom.

\section{Measured Results and Discussion}

The proposed antenna was fabricated on FR4 substrate and overall dimension of the antenna is $54.4 \mathrm{~mm}$ (length) $\times 4 \mathrm{~mm}$ (width) $\times 5 \mathrm{~mm}$ (height). The printed circuit board (PCB) is FR4 substrate with a size of $140 \mathrm{~mm}$ (length) $\times 70 \mathrm{~mm}$ (width) $\times 1 \mathrm{~mm}$ (height). Figure 7 shows the simulated and measured VSWR of the fabricated antenna. The measured results were obtained using Agilent $8510 \mathrm{C}$ vector network analyzer. Bandwidths of 3:1 VSWR in low and high band are measured to be $130 \mathrm{MHz}(830 \sim 960 \mathrm{MHz})$ and $750 \mathrm{MHz}$ $(1550 \sim 2300 \mathrm{MHz})$, respectively. The measured results are in good agreement with the simulated results except for an additional resonance of feeding cable at the high band. Also, the second resonance (loop resonance by big mushroom) at the high band is upshifted by $120 \mathrm{MHz}$ by the fabrication tolerance. The total efficiency and far-field radiation pattern are measured in the anechoic chamber system. The anechoic chamber is composed of shield enclosure (Size $4 \mathrm{~m} \times 2.5 \mathrm{~m} \times$ $2.5 \mathrm{~m}), 18$ inch pyramidal absorber, network analyzer, wireless communication test set, positioner, turn table, and dual polarized transmit antenna. The total efficiency measured in

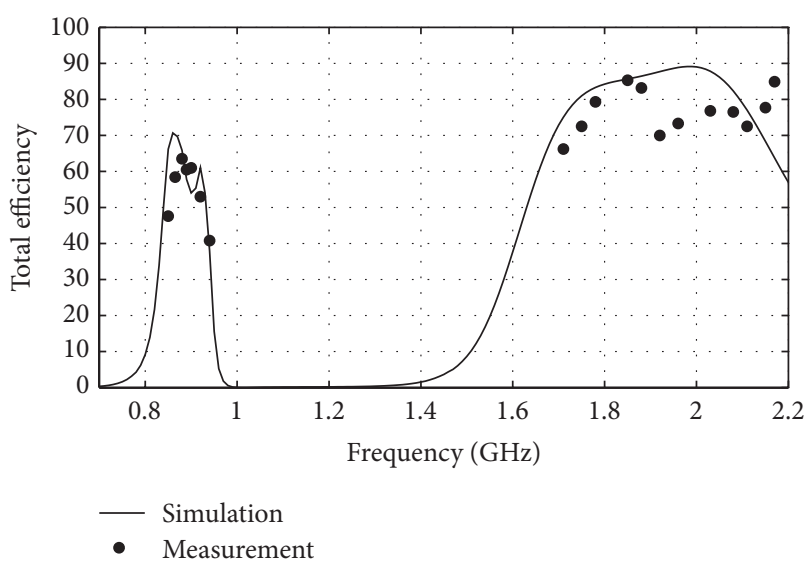

FIGURE 8: Simulated and measured total efficiency of dual ZOR antenna with BSF.

each resonance is $59 \%$ at $870 \mathrm{MHz}, 54 \%$ at $950 \mathrm{MHz}, 78 \%$ at $1750 \mathrm{MHz}$, and $72 \%$ at $2100 \mathrm{MHz}$, as shown in Figure 8 . Figure 9 shows the simulated and measured far-field radiation patterns of the antenna, which are presented at the resonant frequencies. The radiation patterns at $870 \mathrm{MHz}$ and $950 \mathrm{MHz}$ have omnidirectional characteristics at $y-z$ plane that are similar to dipole antenna, because ZOR antenna designed by mushroom has asymmetric and large ground plane, and ground beneath the ZOR is removed. The measured farfield radiation patterns are in good agreement with the simulated results. The slight difference between simulated and measured data is caused by material tolerance and SMA type cable loss.

\section{Conclusion}

In this paper, a multiband antenna with band-stop filter based on dual DNG ZOR for mobile handsets is proposed. To increase the performance of antenna, such as efficiency and bandwidth, we have modified mushroom-like structure with a bended patch and band-stop filter (BSF) on a nonground region. The lengths of each antenna are about $\lambda_{0} / 10$ at the resonant frequencies of $900 \mathrm{MHz}$ and $1800 \mathrm{MHz}$, respectively. The overall dimension of the proposed antenna is $54.4 \mathrm{~mm}$ (length) $\times 4 \mathrm{~mm}$ (width) $\times 5 \mathrm{~mm}$ (height). Bandwidths of $3: 1$ 


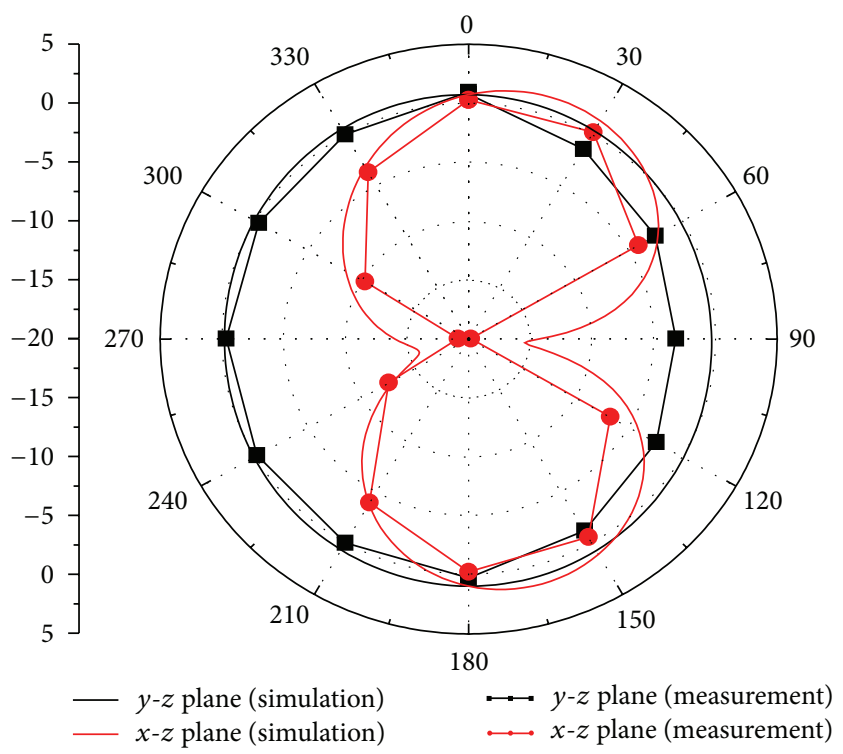

(a)

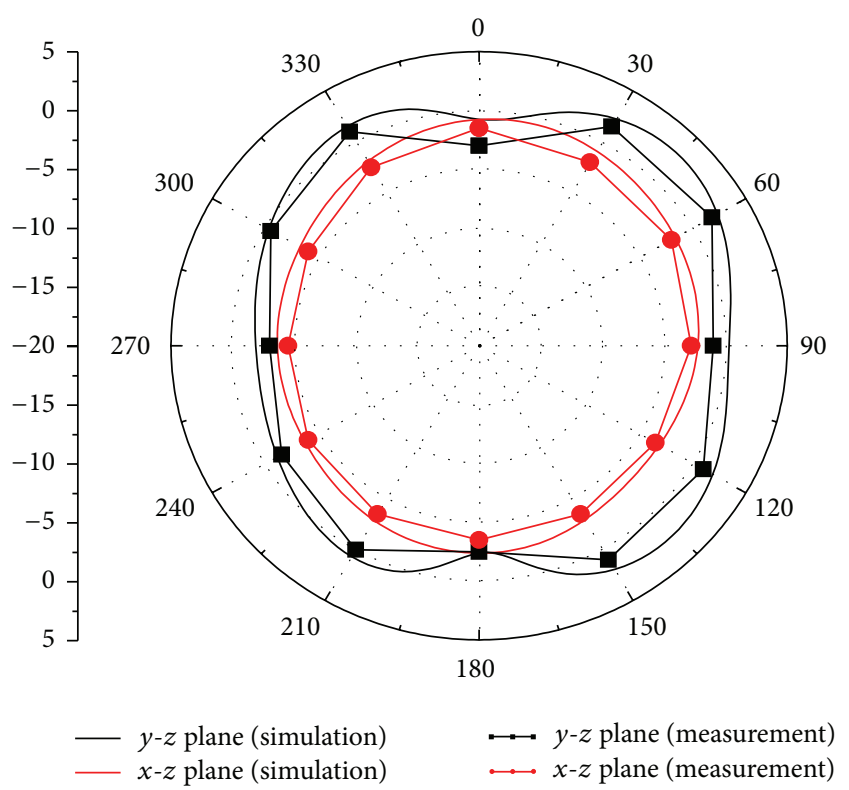

(c)

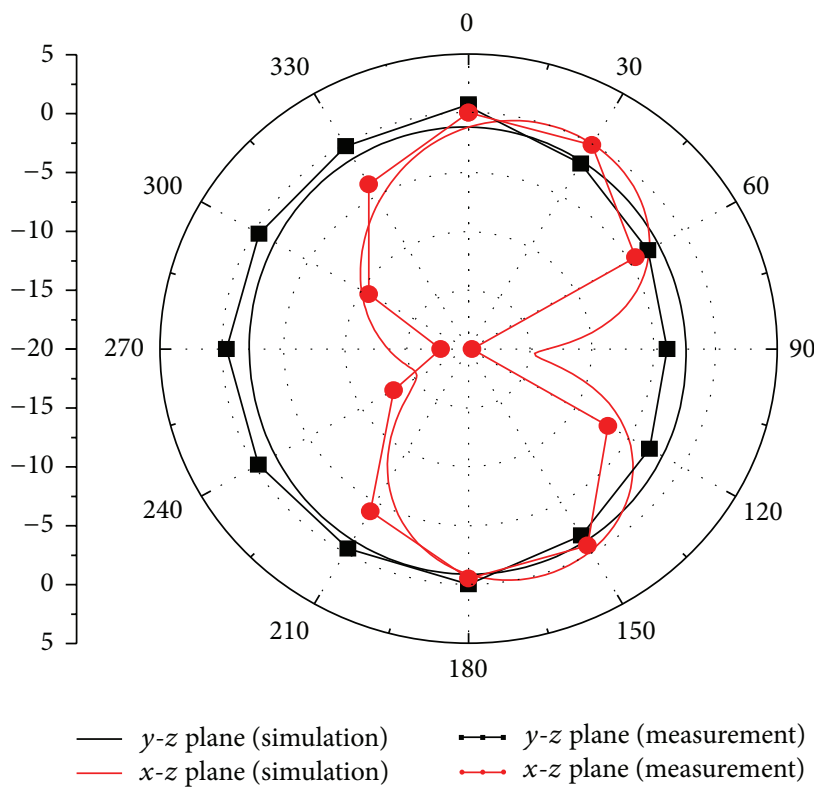

(b)

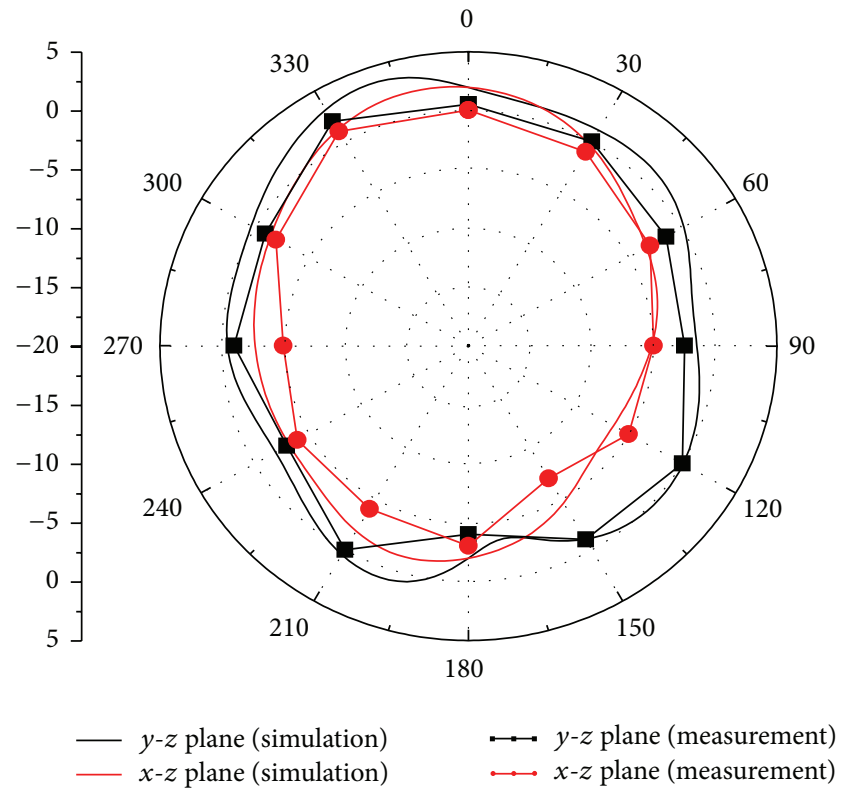

(d)

FigURE 9: Simulated and measured far-field radiation patterns at resonant frequencies (a) $870 \mathrm{MHz}$, (b) $950 \mathrm{MHz}$, (c) $1750 \mathrm{MHz}$, and (d) $2100 \mathrm{MHz}$.

VSWR in low and high band reach $130 \mathrm{MHz}(830 \sim 960 \mathrm{MHz})$ and $750 \mathrm{MHz}(1550 \sim 2300 \mathrm{MHz})$, respectively. Moreover, the total efficiency in low and high band is simulated more than $40 \%$ and $70 \%$, respectively. Thus, the proposed antenna can be used for mobile applications.

\section{Competing Interests}

The authors declare that there are no competing interests regarding the publication of this paper.

\section{Acknowledgments}

This research was supported by Basic Science Research Program through the National Research Foundation of Korea (NRF) funded by the Ministry of Education (no. 2015R1A6A1A03031833).

\section{References}

[1] Z. Zhang, Antenna Design for Mobile Devices, John Wiley \& Sons, Hoboken, NJ, USA, 2011. 
[2] A. Sanada, C. Caloz, and T. Itoh, "Novel zeroth-order resonance in composite right/left-handed transmission line resonators," in Proceedings of the Asia-Pacific Microwave Conference, vol. 3, pp. 1588-1591, Seoul, Republic of Korea, 2003.

[3] J.-G. Lee and J.-H. Lee, "Zeroth order resonance loop antenna," IEEE Transactions on Antennas and Propagation, vol. 55, no. 3, pp. 994-997, 2007.

[4] G. V. Eleftheriades, A. K. Iyer, and P. C. Kremer, "Planar negative refractive index media using periodically L-C loaded transmission lines," IEEE Transactions on Microwave Theory and Techniques, vol. 50, no. 12, pp. 2702-2712, 2002.

[5] J.-H. Park, Y.-H. Ryu, and J.-H. Lee, "Mu-zero resonance antenna," IEEE Transactions on Antennas and Propagation, vol. 58, no. 6, pp. 1865-1875, 2010.

[6] J. K. Ji, G. H. Kim, and W. M. Seong, "A compact multiband antenna based on DNG ZOR for wireless mobile system," IEEE Antennas and Wireless Propagation Letters, vol. 8, pp. 920-923, 2009.

[7] A. Gummalla, M. Achour, G. Poilasne, and V. Pathak, "Compact dual-band planar metamaterial antenna arrays for wireless LAN," in Proceedings of the International Symposium on Antennas and Propagation Society, pp. 1-4, San Diego, Calif, USA, July 2008.

[8] C. Caloz, A. Sanada, and T. Itoh, "A novel composite right/left-handed coupled-line directional coupler with arbitrary coupling level and broad bandwidth," IEEE Transactions on Microwave Theory and Techniques, vol. 52, no. 3, pp. 980-992, 2004.

[9] A. Sanada, C. Caloz, and T. Itoh, "Planar distributed structures with negative refractive index," IEEE Transactions on Microwave Theory and Techniques, vol. 52, no. 4, pp. 1252-1263, 2004. 


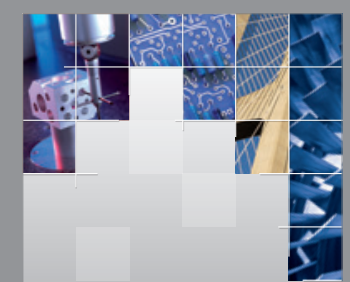

\section{Enfincering}
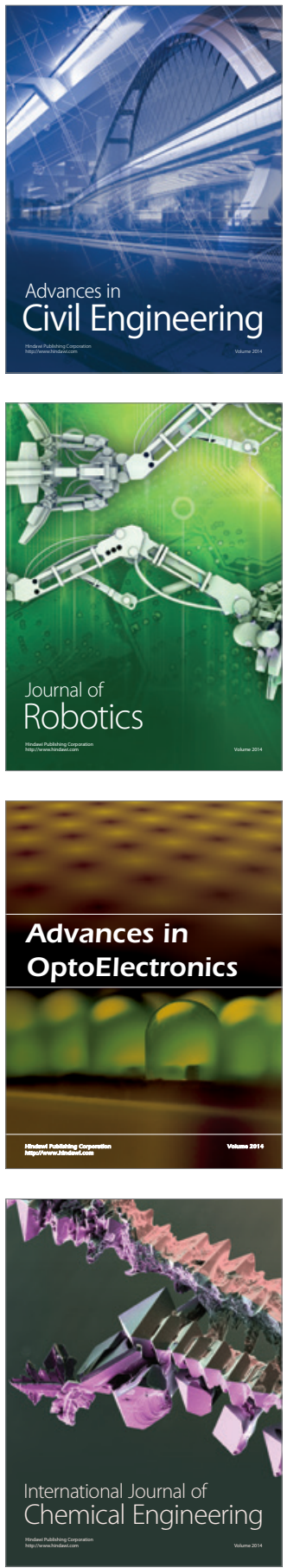

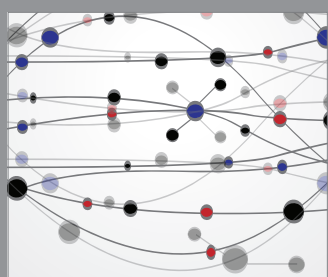

The Scientific World Journal

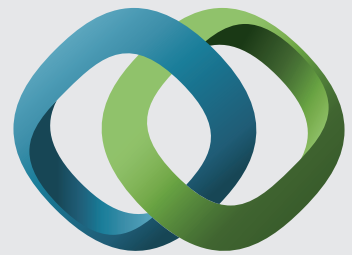

\section{Hindawi}

Submit your manuscripts at

http://www.hindawi.com
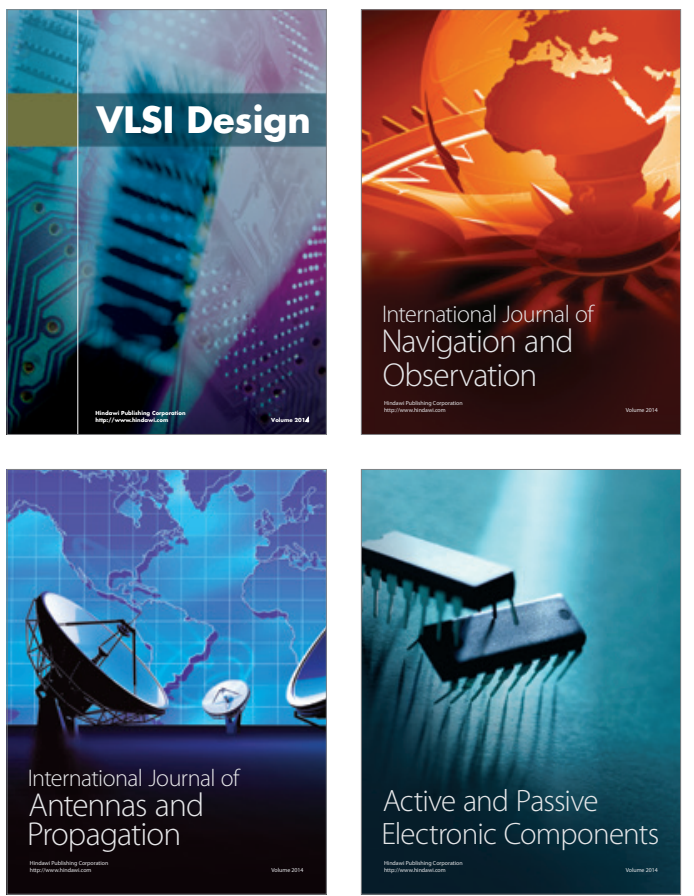
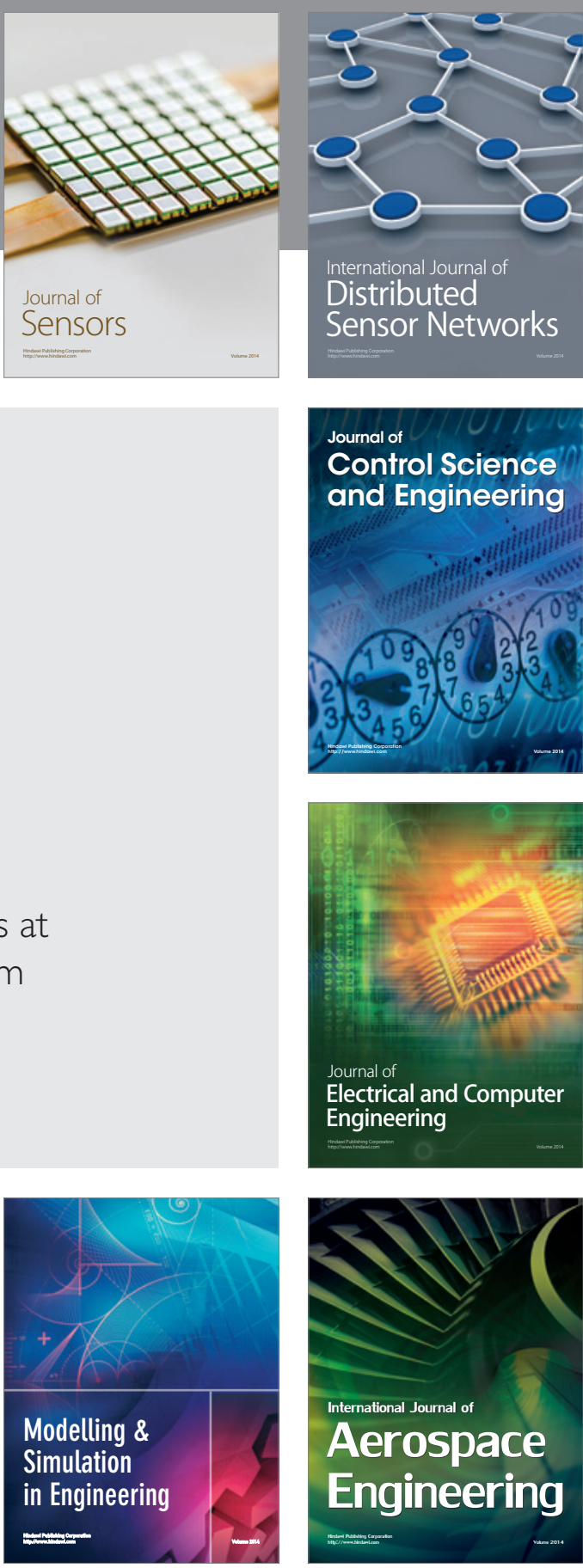

International Journal of

Distributed

Sensor Networks

Journal of

Control Science

and Engineering
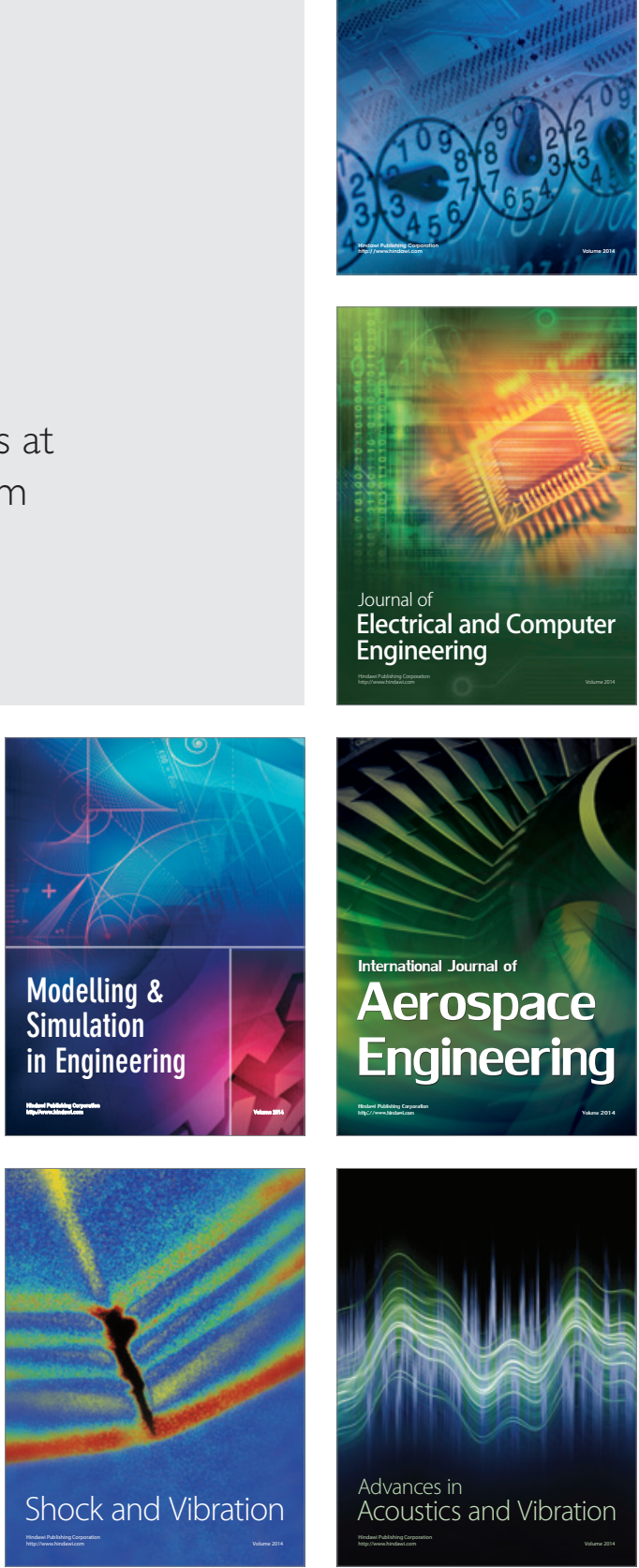